\title{
RICHARD SWINBURNE
}

\section{RESPONSE TO ESSAYS ON ARE WE BODIES OR SOULS?}

Thank you very much to all the contributors to this symposium on my Are We Bodies or Souls? for their kind words and for their very pertinent questions, objections, and amplifications. Inevitably, some of these essays raise similar points and I will consider under the same heading the similar points raised by different contributors, taking first a crucial point relevant to the whole discussion and thereafter taking the other points in the order of the places in my book on which they focus. Alas, for reasons of space, it is not possible to deal with all the objections raised by contributors, but I have tried to answer what I take to be the main objections.

\section{THE “ESSENCE” OF A SUBSTANCE, PROPERTY, OR EVENT}

Several contributors claim that the "nature" or "essence" of a mental event such as a pain, a mental property such as feeling pain, or a mental substance such as a person is an underlying essence which makes these things what they are and which we can discover only a posteriori; it is not something superficial, that is perceivable or experienceable, on the surface of the object, and so it may be something of which any person may be entirely ignorant. Thus, Paul Snowdon claims that a psychophysical theory may well lead us to conclude that "the actual nature of the occurrence such as a pain is that it is a complex and special physical happening." John Cottingham suggested (getting his "cue from Descartes"!) that "to unpack [the] essential nature" of sensations I "would have to unravel their role as part of the complex

Richard Swinburne, Emeritus Professor at the University of Oxford; address for correspondence: 50 Butler Close, Oxford OX2 6JG, United Kingdom; e-mail: richard.swinburne@oriel.ox.ac.uk; ORCID: https://orcid.org/0000-0001-9898-6135. 
psychophysical signaling system whose workings are largely hidden." Howard Robinson acknowledges that a speaker may know to which object they are referring by an expression, but "that does not seem to be the same as having a grasp on the intrinsic nature of the thing to which you are referring." He does not explain what it would be like to have a grasp on the intrinsic nature of oneself, or indeed of anything at all, nor does he explain what an "intrinsic nature" is. But it does rather look as if he also holds that the "intrinsic nature" of an object includes any underlying cause of its superficial properties. Kit Fine argued that that an essence of an object is not any set of logically necessary and sufficient conditions, but rather a particular set which he calls the "definition" of that object. ${ }^{1}$ But I cannot see that he has done any more than to show that his definition of "essence" elucidates what philosophers ordinarily mean by "essence"; and he may or may not be right in this. And it may be that in his sense "the essence" of a property or substance involves any underlying cause of its superficial properties. Nevertheless, I am entitled to my own definitions of technical terms. What I define is "knowing the essence" of some object, and I define it as "knowing $a$ set of the logically necessary and sufficient conditions for being that object" (94; all parenthetical page references are to my Are We Bodies or Souls?).

It seems obvious to me that in my sense of "knowing the essence" any scientifically unsophisticated person knows very well what the essence of pain, that is what a "pain" is - it is the sort of feeling they normally get in such and such circumstances, for example, when someone stabs them with a pin. (As I argue in chapter 5B, we all normally have good, but not infallible, reason to believe that sensations feel much the same to each of us.) Now a philosopher or scientist can use "essence" in a sense in which the essence of a property or substance is something underlying the observable or experienceable which normally causes-that. But it can be misleading to do so if it leads someone to suppose that the superficial features do not really exist. And of course they are just as much part of the real world as the underlying cause; and a philosopher who wants to give a full account of the nature of the world must list them among the things that there are. These superficial features are mental events, properties, and substances, which are directly and often infallibly experienceable by persons who understand them to be what they are quite independently of their underlying causes. I needed a word to describe what one knows when one knows a set of logically necessary and sufficient conditions for something to be the thing it is, because when one knows that about a thing one knows or can work out by a priori reasoning what is logically possible and what is not logically possible for that thing to do or be; and so one is in a position to judge whether what is said

${ }^{1}$ Kit FInE, “Essence and Modality,” Philosophical Perspectives 8 (1994): 1-16. 
to be conceivable, as by Descartes, really is conceivable. I chose "essence" as that word, and that is all I mean by it.

Stanisław Judycki rightly sees the modal arguments of Descartes and myself as examples of "eidetic intuiting" which is concerned with "the essential features" (his words) of qualities (in my terminology "properties") "directly present to consciousness," which he calls "morphological essences" and contrasts with "hidden essences" of things. In the analytic tradition David Chalmers has called this process "modal imagination." It is the a priori process of examining what is involved in being a certain object of experience or perception, for example examining what is involved in me thinking, and so discovering what is entailed by "I am thinking." This process leads us to discover that some sentences entail contradictions, and so are not logically possible, that is (in my sense) inconceivable; and that some sentences are logically necessary, since their negations are inconceivable. Sentences express propositions, and propositions assert the relations of concepts to other concepts: and so the process of analysis of sentences shows how concepts relate to each other. Unless we had some understanding of which sentences entail which other sentences, and some understanding of how to show that some claim about the logical status (logically possible, or whatever) of a sentence entailing another sentence is true or false, rational discussion would be impossible. Judycki makes this point, which repeats the point made by me on pp. $71-72 .^{3}$

\section{CAN THERE BE THOUGHTS WITHOUT A THINKER? (PP. 13-28)}

Stanisław Judycki writes that I do not consider "the difference between a stream of consciousness and the subject distinct from it," and so raises the issue of whether there can be conscious events, such as pains or thoughts, without there being a substance (person, animal or whatever) to whom they belong. I did give a very brief argument on p. 73 for rejecting that possibility: " "thinking' is a property; there can only be an event if some substance has that property." Given my earlier definitions (17) of an event as "a substance having (gaining or losing) a property (or coming into existence or ceasing to exist) at some time," and a "property" as a universal, it follows that conscious events are (or entail other events which are) instantiations of

${ }^{2}$ David Chalmers, "Does Conceivability Entail Possibility?" in Conceivability and Possibility, ed. Tamar Sz. Gendler and John Hawthorne (Oxford: OUP, 2002), 151.

${ }^{3}$ For my detailed account of how to determine whether one sentence entails another sentence, and so what is the logical modality of a sentence, see Richard Swinburne, Mind, Brain, and Free Will (Oxford: OUP, 2014), 16-19 and 44-54. 
properties in substances at times. But of course there are systems of metaphysical categories rival to the substance, property, and event system within which I was operating. In particular, on the trope system, what we would ordinarily classify as a substance which has universal properties is treated as a bundle of particular properties. So if anyone is to defend the view that there cannot be conscious events without there being a substance to which they belong, without getting involved in a general discussion of the viability of some alternative system of categories, they need an argument which supports that view about conscious events without having more general implications for all events. Judycki gives an argument for this in terms of the need for there to be a mental substance to explain the semantic unity among a stream of conscious events. But "semantic unity" is a matter of degree, and whether an event is experienced by a substance is not a matter of degree. In any case, any Cartesian argument has as a premise that at a certain time "I" am having a thought; it is irrelevant to the subsequent argument whether or not that thought is part of a unified stream. So I need a reason to hold that the mere occurrence of a solitary conscious event entails there being a substance which is conscious of it.

My reason is simply that that is just what we are aware of in being aware of a conscious event which we are experiencing. We do experience conscious events, and we would not be aware of doing so unless we were aware of those events as occurring to a substance which is oneself. I could not experience a pain, unless I thought of it as something happening to me, a thing (a substance) which had the property of feeling pain. The distinction between me and the event of the pain or thought is clear from the fact that it is involved in me having the pain or thought that (it is logically possible) I could have had instead of that event a different sensation or thought - and yet it would have been the same me that had it. Someone who denies this does not understand what a conscious event is. What I have written is not so much an argument, but an attempt to get anyone who claims that there can be conscious experiences without a substance which experiences them, to pay attention to what a conscious event is. This provides my justification for the first premise of Descartes's argument and my own amended version of it.

Judycki claims that even if I have shown that "I" is an absolutely simple being, "that is, a magnitude without any parts at all, it does not have to be eternal as it can still lose its reality." I entirely agree that I have not shown that the soul "will last for unlimited time," and I did not purport to do so. But I believe that I have shown that, as a substance separable from its normal sustaining cause, a particular body, a soul could continue to exist if it is sustained in existence by a different cause; and it is logically possible that it could be so sustained and go on existing for ever. So, if there is a God, he could keep it existing everlastingly, either by his direct action or by providing it with a revivified or totally new body. 


\section{THE DISTINCTION}

BETWEEN MENTAL AND PHYSICAL EVENTS (PP. 28-32)

Paul Snowdon claims that I have not shown that mental events do not supervene on physical events, because I have not shown, for example, that there may not be a very complicated physical description of me when I am in pain which he calls "SBP," which entails the conclusion "a human is in pain" which he calls "P," and could be shown to entail it by a very sophisticated proof. He suggests that I would need to "propose a theory of deductive reasoning which reveals that no such deduction can ever be discovered." But no one could produce a proof that a sentence of the form SBP does or does not entail $\mathrm{P}$ without proposing some plausible axioms about the meanings, and so about the most immediate and obvious logical entailments and compatibilities, of such words as "pain" and "physical description." So we could not begin to formulate such a proof until we had settled what we mean by the proposition that a human is "in pain." That can only be done if we reasonably assume that most people mean more-or-less the same as each other by "in pain." As I suggested in section one, to say that someone is "in pain" is to describe a directly experienceable feeling; and, I now add, that (unlike some other mental events) it is an event of a kind such that the subject knows infallibly when they are "in pain." If there were an SBP which entailed P, then a physician would be entitled to say to a patient who honestly claims that they are not in pain, "anyone can see that you are in [the relevant] SBP, and so you are mistaken in denying P." This is massively implausible; people know infallibly whether or not they are in pain. If Snowdon thinks that to say someone is "in pain" is such that it is epistemically possible that it is entailed by some bodily cause or essence, then we must invent another word "fain" that has the meaning that I claimed that most people ascribe to the word "pain," and then my claim is that fains, which we are all aware of having, are mental events which do not supervene on physical events.

Paul Snowdon then claims that my attempt to distinguish physical events from mental events by the former being such that no one can have privileged access by experiencing them, while mental events are such that only one person can have privileged access to them by experiencing them, does not make the sharp distinction which I was seeking to make. He adduces various examples of events which, he claims, I might wish to classify as physical but might equally well be classified as mental. These examples suggest that I may not have made sufficiently clear what I mean by "having privileged access to them by experiencing them." I have "privileged access" to an event iff necessarily I can know better than can anyone else whether or not the event is occurring. I have "privileged access to an event by experiencing it" iff necessarily the means by which I know that it is occurring better than anyone 
else is by experiencing it. Given that clarification, I do not think that any of Snowdon's purported counterexamples to my claims about which events are mental and which events are physical, have any force. Thus, Snowdon claims that in fact I have privileged access to what I had supposed to be a physical fact that there is a tree in front of me. I deny that I have such privileged access. Anyone else can discover this fact as well as I can; and since I do not have privileged access to it, I do not have privileged access by experience to it. (I do of course have privileged access to the fact that I am seeing the tree.) Snowdon claims that we have privileged access by experiencing them to such evidently physical facts about our bodies as the positions of our legs. I deny that we have privileged access to such facts; anyone else can find out about them as well as I can, and sometimes better. So it is irrelevant whether or not I experience them. I should emphasize also that my distinction concerns what we "can" experience, and by "we can" I meant "it is logically possible that we." And while of course normally only you actually experience (= feel) the position of your leg, an apparatus could (not merely logically, but practically) be constructed which connected your nerves to my nerves in such a way that I too could experience the position of your leg, and my access to its position would be just as good as your access to its position. And presumably Siamese twins who share some of the lower parts of their body do actually have equal access to the position of a shared leg. But any attempt to connect my brain to your brain in such a way as to allow me to experience a sensation which I believe to be qualitatively similar to your sensation will not give me the kind of privileged access to your sensation which you have. This is because (as I point out in chapter 5) there will always be some doubt about whether the apparatus connecting our brains does give me a qualitatively identical experience to yours; but there cannot be any doubt about whether I am having the experience which I experience myself to be having. One Siamese twin may know very well what the other Siamese twin is feeling, but there is always the possibility that the former misunderstands the latter. So I do have privileged access to my sensations and the other events which I classified as "mental," but not to the ones which I classified as "physical"; and the distinction between them is a sharp one.

Snowdon also queries my account of certain events which I describe as "mental" because one has privileged access to them, and so knows about them by experiencing them. He points out rightly that a subject does not know about an experience by having an experience of that experience. But all I meant by "knows about them by experiencing them" is that experiencing them entails knowing about them. An event is mental only if knowing about it is part of what experiencing it involves. Snowdon also denies that one can know about some of one's beliefs by bringing candidate beliefs to consciousness and asking oneself whether one believes them. But I often do just this. I formulate in words some candidate belief, and then it is 
obvious to me that I do or do not believe it. Of course, it is not merely saying to myself the sentence "Einstein is a genius" or "God exists," but a matter of the conviction which sweeps over me when I say to myself, either that I believe it or that I do not. Of course, with most of my beliefs I do not need to go through this process in order to know whether or not I have them, but the process is available and it is what makes my belief a mental event.

Finally, Snowdon suggests that I would only be justified in making the distinction between physical events and mental events in the way that I do, if I had drawn up a long list of events which we all call "physical" and a long list of events which we all call "mental" and found that my way of distinguishing them fits all those cases. But that was not what I was doing, and our ordinary language use of the two words is too vague for this to be a useful exercise. What I was doing was drawing attention to a clear distinction in terms of whether there is privileged access to them by experiencing them, between two types of events in the world, one of which would fit many examples of events which we naturally call "mental" and the other of which would fit many examples of events which we naturally call "physical." If there are some events which we naturally call "mental" but are not "mental" on my definition, and similarly for "physical," that does not matter - as my definition was only seeking convenient words to "carve reality at the joints."

\section{HALF-BRAIN TRANSPLANTS AND THE SIMPLE THEORY OF PERSONAL IDENTITY (CHAP. 3)}

I originally defined a "complex theory" of personal identity (7) as a theory which analyses a later person being the same person as an earlier person "in terms of the later person having some of the same body or some of the same physical or mental properties as the earlier person"; and (8) a "simple theory" as one that held that no such analysis was possible. I then proceeded in chapter 3 to discuss how we should interpret the possible results of various thought experiments, and claimed to show that no complex theory of personal identity could provide a satisfactory account of them; and so concluded that we should prefer a "simple theory." Unfortunately at that stage, as John Schwenkler rightly points out, I gave a different definition of a "simple theory" as one which held that "there are no necessary or sufficient conditions for personal identity in terms of the degree of any feature of which there can be degrees" without explaining its connection with the earlier definition. I apologize to my readers for this omission. The connection is that the discussion of the different thought experiments showed that all complex theories were open to the "arbitrariness objection," arising from the fact that all the features in terms of which they 
attempt to analyze personal identity - continuity of body, brain, mental or physical properties - were all features of which there is a continuum of possible degrees (and that any "partial identity" version of such theories would be incoherent). Hence, I concluded that any analysis of personal identity in terms of any other feature of which there could be degrees would give rise to the same problem, and so I moved to a wider definition of a "simple theory."

My main thought experiments concerned cases where some of the brain of one person was taken out of their skull and put into the skull of another person from which the corresponding part had been removed and connected up to the rest of the latter's brain. Schwenkler doubts whether such operations are possible without killing those involved. I am inclined to think that the half-brain transplants which I discuss are physically possible. As I mention on pp. 47-48, on quite a number of occasions surgeons have removed a whole functioning hemisphere, leaving the patient with similar memories and character and able to function fairly well. So what Schwenkler is suggesting must be that attempting to implant into such a patient a new half-hemisphere would kill the patient. I doubt that; it seems less plausible that implanting something into a patient would kill them than that removing something from a patient would kill them. There are now serious medical plans aimed at achieving a head transplant (which would involve transplanting also the spinal cord). But suppose that Schwenkler's doubts proved justified: and that any attempt at all to transplant a brain hemisphere would lead to the death of the intended recipient. Nevertheless, it suffices for the cogency of my argument that what I describe as "possible" is merely "logically possible." If there is no contradiction in the claim that there could be a person who had half their brain replaced by a half-brain taken from another person (as Schwenkler implicitly acknowledges in allowing that science might in fact show it to be true), that shows that it is not essential to the identity of a person that none of their brain parts are obtained from another person. And a similar result follows for all thought experiments which I considered.

William Hasker discusses my thought experiment where Alexandra is captured by a mad surgeon who plans to transfer each of her two brain hemispheres into the skulls of two different persons from whom the corresponding brain hemisphere has been removed and connect Alexandra's hemisphere to the other parts of the brain of the receiving person. After the operation the surgeon proposes to kill just one of the subsequent persons. Alexandra is given the choice of whether it is the person with her left hemisphere who will be killed or whether it is the right person with her right hemisphere who will be killed. In attempting to rebut a "semantic indecision" theory, I wrote: "Surely there is a truth about whether or not Alexandra will survive." Hasker comments that this remark "is persuasion, not argument," since any partial identity theory claims that "it is impossible that (there is no possible world in which) that assertion is either straightforwardly true or straightforwardly 
false." This remark of mine was only intended to draw the reader's attention to the apparent implausibility of any partial identity theory. We should not adopt an apparently implausible view unless it can solve some problem suffered by the normal view. I went on to claim that for various reasons all partial identity theories were open to various decisive objections. Hasker then presents a thought experiment of his own which seems to differ from my thought experiment only in the respect that its subject, "Tubby," believes himself to be identical with both post-fission persons. But this is open to the objection that each of these post-fission persons may have different subsequent experiences unknown to the other person, and so cannot be the same person as that other person-Tubby's belief is incoherent. And it is not plausible to suppose that the death of one of these persons will cause the other person to be the same as the original person; one person dying cannot make another person a different person from the person whom he would otherwise be. Hasker then seems to suggest that the original person might not mind whether she continued to exist, so long as some later person continued to exist with some degree of continuity with herself. Derek Parfit claimed that degree of continuity with a past person was far more important than identity with a past person. ${ }^{4}$ But that does not show that there is not a truth about whether or not some later person is identical with oneself; and some, and I suggest almost all, humans care very much about whether they continue to exist after some brain operation or even their bodily death.

Howard Robinson does not think that my analysis of my thought experiments about half-brain transplants "will convince anyone tempted by complex physical or mental continuity theories," to adopt the simple theory of personal identity. I hope and believe that he is mistaken about this. However, I fully welcome his own arguments in defense of the simple theory of personal identity, which appeal to "counterfactuals of origin"; and I entirely endorse what he writes about such counterfactuals. They provide an entirely different and compelling strand of argument in favor of that theory; I was well aware of this strand of arguments, and regret that I did not incorporate it into my book. However, it seems to me that opponents of the simple theory will answer his "Would it have been me?" questions about the person that emerged from the slightly modified sperm in terms of that person would have been " $85 \%$ of me." I agree that that answer "makes no sense," but I suggest that the kind of reason which Robinson offers for why it "makes no sense" is of the same kind as the reasons which I gave for supposing that it makes no sense to suppose that the future person formed of some of my brain will be "partly identical" with me. "Empathy," which Robinson stresses, seems to me to be involved in both kinds of example.

\footnotetext{
${ }^{4}$ Derek PARfIT, Reasons and Persons (Oxford: OUP, 1984), part 3.
} 


\section{THE IDENTITY OF COMPOSITES (PP. 68-70) \\ AND METAPHYSICAL POSSIBILITY (APPENDIX TO CHAP. 5)}

My principle of the identity of composites is that "if a substance exists for a certain period of time and has certain substances as its parts, and these parts have the same essential and non-essential properties, then it is not possible if these parts exist in the same arrangement having the same essential and non-essential properties for that period of time that they could form a different substance from the one which they do form." I used this principle to argue that if half of Alexandra's brain is transplanted into the skull of another person so as to replace the half-brain in that skull, and the resulting person acquires some but not all of the physical and mental properties of Alexandra while retaining some but not all of the physical and mental properties of the other earlier person, then "the resulting person is Alexandra" and "the resulting person is not Alexandra" are both logically possible. John Schwenkler asserts that it may be that one of these alternatives is not really "metaphysically" possible, and a non-dualist is perfectly entitled to claim that on the basis of "a theory on which the identity of a person is fixed by the physical facts about him or her." In recent years many philosophers have made claims that some proposition has or may have a certain metaphysical modality without giving any account of what it is to have that metaphysical modality, how anyone could establish that a proposition does have that metaphysical modality, and how their particular claim could be established. Now of course Schwenkler could not be expected to do all that in a short essay. And as this book was intended in part for an audience much wider than that of professional philosophers, I avoided discussion of metaphysical modality in the main part of the book. But, feeling the need to meet objections of the kind which Schwenkler makes, I gave a very brief account in the Appendix to chapter 5 of my account of the relation between metaphysical and logical modality. This is that a sentence (and so the proposition which it expresses) is "metaphysically possible/impossible/necessary iff it is logically possible/impossible/necessary when all its uninformative rigid designators are replaced by informative designators of the same object." I argued in chapter 5 that 'I' and one's own proper name as used by oneself are informative designators of persons, and that a proper name of some other person with a certain body is used to refer to whoever the person with that body would use it to refer to. Hence 'Alexandra' (as used by Alexandra) is an informative designator of the person with a certain body before the transplant. It follows that, since all the other words in these sentences (and the sentences which describe the transplant) are also informative designators, that since "the resulting person is Alexandra" and "the resulting person is not Alexandra" are both logically possible, they are also both metaphysically possible. Although I did not in the Appendix ap- 
ply my account of metaphysical modality to this particular example, I did apply it to one of the premises in Descartes's argument, and its application to the particular argument now being discussed should be apparent. I think that Schwenkler ought to have taken account of this discussion. Much of my book was designed to show that what Schwenkler asserts that "a non-dualist is perfectly entitled to claim," is false.

\section{DESCARTES'S OWN ARGUMENT (PP. 70-76)}

I claimed that the major error in Descartes's original argument, was that what I called the lemma "I am a substance which, it is conceivable, can exist without a body" does not entail the conclusion "I am a soul, a substance, the essence of which is to think." Howard Robinson argues that my objection is mistaken: the lemma does entail the conclusion - given that "conceivable" means "logically possible." I am using "conceivable" to mean "logically possible," and I maintain my claim that the lemma does not entail the conclusion. For all that the lemma claims is that it is not logically necessary for my existence that I have a body, and so that having a soul is logically sufficient for my existence. It does not show that having a soul is logically necessary for my existence. Robinson writes: "If it is logically possible that I exist without a body, then I am not identical with or logically necessarily in any way related to my body, for if I weren't necessarily related to it, it would not be logically possible that I'd be without it." He is right in claiming that the antecedent of this conditional entails the first disjunct of the consequent: "I am not identical with my body"; but I am unclear what the second disjunct meanswhat does it mean to be "logically necessarily in any way related to my body"? There are logical relations weaker than identity. For it may be, compatibly with the lemma, that necessarily my body is sufficient for my existence. To put the point in possible world terms: it does not follow from there being a possible world in which I exist without a body, that there is not a possible world in which I exist without a soul. Hence, I claimed, the lemma is compatible with "what is necessary and sufficient for Descartes to exist, what his whole essence consists in, is to have either a body or a soul (or both)"; to show more than that, we need my amended version of Descartes's argument. This amended version contains an amended second premise, that it is conceivable that my body is destroyed and yet I continue to think. That would not be conceivable if while I had my body, I did not have also a soul, because in that case when my body was destroyed, all its and so my parts would be simultaneously destroyed and so I could not continue to exist. So if at every time it is conceivable that I continue to exist while my body is destroyed, my soul must be at all times necessary for my existence, while my body is never necessary for 
my existence. I sought to motivate my amended second premise by describing a situation in which all causal interaction between a person's continuing experiences and their body ceased; and yet the person continued to have experiences quite independently of bodily events. This is what those who claim that there are real "out of the body" experiences are claiming, and I suggested that we can easily understand that as a coherent claim, even when - as normally — we do not believe it to be true. I claimed that if all contact between a person and their body ceased, they would no longer "have" a body. But if someone denies this, let us add to the thought experiment that when causal interaction ceased the body was destroyed; since all causal interaction had ceased, that would make no difference to the person's experiences, but — even more obviously - the person would not have a body. And yet, I suggest, we can understand the claim; it is conceivable that experiences do continue, if only for a whole second, after the destruction of the body. If so, the amended second premise is true.

\section{THE CLOSENESS OF THE SOUL-BODY UNION}

(ESPECIALLY PP. 73-74, 84)

Several contributors stressed that the union of mind and body, and so on my account the union of soul and body, is far closer than my account seems to allow. I claimed on pp. 73-74 that "to have a body ... is to have a chunk of matter through which one can make a difference to the physical world..., and through which one learns about the world." Charles Taliaferro objects that this account "does not come close to appreciating the functional unity of person and body. You actually function as an embodied being with all your senses ... appetites, desires, motives, thinking, actions, and the like." I entirely agree with Taliaferro's point. All of these properties of us are wholly or partly properties of our souls and are partly caused by our bodies - both by the genes we inherit, and by the life experiences to which our bodies are subject; and our choices about what to do through our bodies make a great difference to what those bodies are subsequently capable of doing and their subsequent influence on our souls. My sentence (73-74) was merely describing the necessary and sufficient conditions for any conscious being to "have" a body; humans certainly have (contingently) a more intimate connection with their bodies than that. I did not discuss in this book - for reasons of space, and so as not to overcomplicate my argument - whether the human soul normally has properties other than conscious properties and the capacity to have conscious properties. Elsewhere I distinguish between what I called the "dispositional theory" and the "categorical theory" of non-conscious mental states, such as desires and beliefs which continue 
to exist while we are not conscious of them. ${ }^{5}$ On the "dispositional theory" the continued existence of such states consists simply in the occurrence of brain states in us which influence our actions and give our souls (and so us) the ability to become conscious of those mental states from time to time. On the "categorical theory" that continued existence consists in the existence of those non-conscious mental states as sub-conscious mental states of our souls, different from other mental states of the soul simply in being sub-conscious. On balance I favored the categorical theory; and, if this theory is correct, it answers John Cottingham's objection that my account of the soul is "too thin." But whichever of these theories I adopt, I do not wish to deny Charles Taliaferro's claim that the interaction of soul and body gives to humans a rich character of "appetites, desires, motives, thinking, actions, and the like." Eric Olson claimed that on my theory "because the soul shares no parts with the brain ... we should expect those of its activities that don't involve sense perception to continue unhindered, even when the brain is not working properly." I simply do not follow why we should expect this. On my account throughout the life of a human being, their body keeps their soul in existence together with that whole system of beliefs and desires, even when we are not conscious of them. I also claimed (84) that "having a body means that there is some place where other people can get hold of us, and we can get hold of them; and we can share the enjoyment of a common public world." John Cottingham suggests that this shows that my conception of my body is an instrumental one - my body is something that is useful to me in enabling me to do certain things. But this ignores the crucial point much emphasized both by modern psychologists and by theologians who stress the centrality of the "resurrection of the body" as a communal event, that those "certain things" are centrally essential to human flourishing.

\section{CARTESIAN SUBSTANCE DUALISM VERSUS THOMISTIC HYLOMORPHISM (PP. 80-85)}

I argued that the differences between my Cartesian theory of the relation of soul and body and the theory of Thomas Aquinas are "almost entirely terminological," arising chiefly because each of us understands the term "substance" in different ways. For me the soul is a substance because it satisfies my definition (13) of a substance as a component of the world which has properties, and it is a separate substance from the body because it is logically possible that it can exist independently

\footnotetext{
${ }^{5}$ Swinburne, Mind, Brain, and Free Will, 85, 167-69.
} 
of the body. Aquinas denies that that is enough to make the soul a substance, because for him substances are independently acting things, and so, he claims, cannot be composed of other substances; hence if the soul is part of an (embodied) person which is a substance, it cannot itself be a substance. But when I try to perform an intentional bodily action, whether I succeed or not depends on whether my nerves act so as to exert the right amount of causal influence on my muscles in a way that could be replicated outside my body (in the same way as is regularly demonstrated in laboratories in a "nerve-muscle preparation" of nerves and muscles taken from a frog's body.) It would seem to follow that if I am a substance and a substance is an independently acting thing, then this substance consists of parts including nerves which are themselves independently acting parts. To say that the senses of "acting" differ according to whether the bodily parts which "act" are inside or outside the body seems to me to fail to bring out what is happening. My simple definition of "substance" "carves reality at the joints."

Jeremy Skrzypek objects that "surely not all collections of objects count as substances," and he asks: "Which collections do count as compound substances and which do not?" My answer is that all of them are substances, but one does not need to mention all of them when describing some segment of the history of the world. We are normally interested only in the behavior of collections of substances of certain kinds which have a significant degree of internal causal interaction and relative independence of their environment. But some scientists are interested in the behavior of those substances which are fundamental particles of which larger objects, including living objects, are composed. One could recount the whole history of the world without mentioning some substances - one need not recount at all the fates of some trees, if one recounts what happens to each of the fundamental particles which together constitute each tree. But one would need to recount what happens to each simple substance (that is, each substance such that it is logically impossible that it could be divided) or to describe something which entails that, and souls are- - I argued - indivisible of logical necessity. So one could recount what we would normally call the whole history of me, by describing separately what happens to my soul (the essential part of me) and what happens to the body with which the soul interacts (an alternative which Skrzypek offered me), without treating my body as part of me. But the degree of functional unity between a person's soul and the connected body is so great, that this would be a very unnatural way of talking, especially if our interest is in the intentional actions and reactions of persons. Yet if someone's body is destroyed and their soul continues to exist, no history of the world will be complete unless one mentions that there is a thing, a soul, not connected to a body, which has properties, and is the same thing as was previously connected to a body. Aquinas's aim of describing everything about the world by the hylomorphic 
scheme involves him having to say that after the destruction of a person's body, there is a thing which has properties and acts and is acted upon but is not a substance; it is, according to him, a form - but a form of such an extraordinary kind (in being capable of existing apart from matter, and instantiatable only in one chunk of matter at any particular time) as clearly to be much more like a substance (even in Aquinas's sense) than like a normal form.

Skrzypek also raises the so-called "too many thinkers" problem. He acknowledges that on my account me thinking may be the same event as my soul thinking but claims that "there are still two things thinking my thoughts." But if the events are the same event, any differences in the description of the substance involved in that event must be just that — different descriptions of the same substance, one of them ("my soul") more precise than the other one ("me") in describing which part of the latter one has the relevant property ("thinking"). Yet since, given the arguments of my book, the only way I can think is by my soul thinking, and the only way my soul can think is by me thinking, I suggest that both of these descriptions of the event describe what is happening in an equally "strict, primary sense."

\section{WHY CANNOT A MATERIAL THING HAVE MENTAL PROPERTIES? (ESPECIALLY CHAP. 4)}

Eric Olson wrote: "Any version of dualism requires there to be an account of why it is metaphysically impossible for a material thing to have mental properties." $\mathrm{He}$ states that he means by a "material thing" a "being made entirely of matter, that is of the atoms we learn about in science class." He clearly needs a more comprehensive definition of "material thing," since presumably he does not wish to rule out the possibility of there being material things not composed of atoms. But since what is essential to his understanding of a "material thing" in this context is that it is a substance which does not have a soul as a part, I will understand his claim as the claim that any version of dualism requires there to be an account of why it is metaphysically impossible for a substance which does not have a soul as a part to have mental properties. Like Leibniz, Howard Robinson claims that "the notion of a brain actually experiencing or apprehending something as the conscious subject, as opposed to sustaining such a thing, does not make sense." But that is not obvious, and Olson's request for an account of why it is metaphysically impossible for a material thing (as defined above) to have mental properties does need to be answered. My answer is that any substance who has a mental property - that is, in Descartes's sense, "thinks"could, if sufficiently logically competent, apply my amended version of Descartes's argument to itself, which would lead it to the conclusion "I am a soul, a substance, 
whose only essential property is the capacity for thought" (79). Of course, many such substances do not have the logical competence to apply this argument. But we can do it for them by replacing in the argument on pp. 78-79 the words 'I' by 'it', 'my' by 'its', and 'am' by 'is', and then the new second premise "it is conceivable that "while it is thinking, its body is suddenly destroyed" will lead to the conclusion "it is a soul, a substance, whose only essential property is the capacity for thought." Hence any substance which has a mental property must have a soul as an essential part. By my own later argument, only a mental substance itself can know what it is to be that individual substance; we outsiders do not have the necessary privileged access which would enable us to know this. However, we do know what it is to think, that is to be conscious; and since we can conceive of any being who is conscious ceasing to have control of (and so to have) a body, and yet continuing to think (and so the new amended second premise would be true of it) and so to exist, such a being must be a being whose only essential property is the capacity for thought, that is a soul.

\section{LOGICALLY NECESSARY AND SUFFICIENT CONDITIONS}

(CHAP. 5)

William Hasker sees no good reason to accept the assumption that "a set of logically necessary and sufficient conditions for being [a certain] person entails all other sets of logically necessary and sufficient conditions for being that person"; and so objects to my claim that if one set of logically necessary and sufficient conditions for being a certain person does not entail that person being embodied, it follows that being embodied is not a necessary condition for being that person. I meant by "a set" of such conditions for an object (substance, property, or whatever) to be the object it is, "a set of logically necessary conditions, such that together they form a logically sufficient condition." If we knew how to recognize such conditions for being a particular object, we would know how to recognize whether any object was that particular object. I may have been careless in assuming that readers would understand my phrase in this way. I did not mean by "a set of logically necessary and sufficient conditions" just a set of some of the necessary and sufficient conditions for an object to be a particular object. I apologize to Hasker and any other readers for any ambiguity on my part leading to any misunderstanding of that point. But, unless Hasker has misunderstood me, I find his objection very odd. For suppose that A, B, and C are necessary conditions for being $\mathrm{P}$, and (A \& B \& C) is a sufficient condition for being P. It follows that for any D compatible with (A \& B \& C), (A \& B \& C \& D) will also be a sufficient condition for being $\mathrm{P}$. If there was an additional necessary condition E, not entailed by (A \& B \& C), then (A \& B \& C) would not be a suf- 
ficient condition for being P. And if there was an additional sufficient condition F, incompatible with ( $A \& B$ \& $)$, then one of $A, B$, or $C$ could not be a necessary condition. So it follows from $\mathrm{A}, \mathrm{B}$, and $\mathrm{C}$ being necessary conditions, such that their conjunction forms a sufficient condition for being $\mathrm{P}$, that any other set of necessary conditions, such that their conjunction forms a sufficient condition for $\mathrm{P}$, will be logically equivalent to (A \& B \& C); and that any other sufficient condition for being $\mathrm{P}$ will be such as to entail (A \& B \& $\mathrm{C}$ ) and so have the form (A \& B \& $\mathrm{C} \& \mathrm{D}$ ).

All that Hasker's discussion of $\mathrm{H}_{2} \mathrm{O}$ shows is that "water" is ambiguous; one can understand "water" in a narrow sense in which heavy water does not count as water, or in a wide sense in which heavy water does count as water: and then my argument goes through for the necessary and sufficient conditions of "water" in each of its separate senses. In Hasker's other example against my claim about the necessary and sufficient conditions of an object, he supposes that Alexandra is "able to conceive" that her "life is in effect divided and continues in the lives of each of the surviving persons, neither of which is strictly identical with Alexandra." The word "conceivable" is alas often used by philosophers in different senses. I state explicitly (14) that I use it in the same sense as "logically possible." Then to "conceive" some state of affairs, is to "see," not merely to believe, that it is logically possible. Hence I deny that Alexandra is able to conceive that her life is divided; she may believe that she can conceive this, but — if the argument of my book is correct — she cannot actually conceive it. I conclude that the inference schema which Hasker sets out under the name "Exclusion" is not merely valid, but sound.

\section{THE NEED TO EXPLAIN THE POWERS AND LIABILITIES OF THE SOUL (CHAP. 7)}

Eric Olson argues that kind of dualism which I eventually claim to have established is badly deficient in not being able to explain how it is possible for an immaterial thing to think (his question 3) He claims that the dualistic view that the soul has the capacity to think requires to be supplemented by an account of what it is in it that gives it that capacity. The physical sciences explain the behaviour of medium-sized objects in terms of the fundamental particles of which they are made and the properties of those particles, but "the properties of souls that are analogous to physical properties ... are unobservable." The main point to be made in answer to all complaints of this kind- "Your theory postulates X but it cannot explain why $\mathrm{X}$ exists"-is that that all human attempts to explain anything have to stop with something that they cannot explain (and, not implausibly, all explanations, in the sense of true accounts of the reasons why things are as they are, have to stop with 
something which just is how things are). Physicists may be able to explain why there are the fundamental particles that there are and why they have the properties which they do: but the explanation will postulate some entities and properties of other kinds which they cannot explain. That there are souls and that they are caused by a brain and continue to interact with that brain in a certain way may itself be something that cannot be explained further (by humans, or at all); and, if so, that is not as such a good objection to the theory that souls exist. On the other hand, there are maybe some feature of that theory (for example, that it is extremely complicated) such that, if a simpler super-hypothesis which makes that theory probable can be found, then that simpler super-hypothesis probably provides the true explanation of the theory. I argue elsewhere that the existence and action of God constitute that simpler super-hypothesis; ${ }^{6}$ but if that super-hypothesis is rejected and no substitute can be found, that does not constitute a good objection to my soul theory.

\section{SOULS HAVE THISNESS (PP. 169-71)}

On my view that souls have thisness, because laws of nature determine relations between substances which depend only on their properties, while there could be a law determining that all foetuses whose brains have certain physical properties cause the existence of a soul of a certain kind (for example, a soul of a person), no law could determine which soul (and so which person) that would be. Hence on a naturalistic view, there could be a law determining that each foetus would cause the existence of a soul, but it would be probabilistic in not determining which particular soul (and so person) that would be. There would only be an infinitesimal probability that it would cause the existence of any particular one of the innumerable possible souls that it could cause. This law would be of a kind quite different from any other kind of probabilistic law known to science. Such laws as the law which determines that a particle passing through a slit will land on some point on a surface without determining which point that will be, nevertheless determines for each particular region of the surface a finite probability that it will land on a point within that region. It can do this because points have numerical coordinates, and so lie within ranges of values of those coordinates. But the possible souls which might be caused to exist by a foetus-soul law do not differ from each other in respect of any measurable quantity, and so there cannot be a finite probability that the soul produced will be one having a value within a range of some quantity.

\footnotetext{
${ }^{6}$ For example, in my The existence of God, 2nd ed. (Oxford: OUP, 2004), esp. 192-212.
} 
On a normal theistic view, such as the view which I have defended at length elsewhere, God causes the operation of laws of nature, and also determines which persons will exist. Hasker claims that the view that souls have thisness is very difficult to accommodate within this theistic framework. In writing Are we bodies or souls? I sought to produce cogent arguments for my view that humans are essentially souls, which in no way depend on any religious assumptions, and which-I hoped-would appeal equally to atheists and religious believers. So I tried to keep "God" out of this book. But Hasker is entitled to require that my philosophical views on different topics should fit together well; and so here briefly is my account of how my view that souls have thisness fits with theism. Hasker correctly claims that, in order to cause the existence of each particular person by means of the operation of laws of nature God would need to do more than keep those laws operative. He writes that God would need to be active within the operation of the soul-producing law, "so that this process, which in itself is incapable of producing any particular soul, will in fact produce the exact soul God has chosen for it to produce. Furthermore, God's being so active [would be] a matter of metaphysical necessity.... The supposition that, on each and every such occasion, God is metaphysically constrained to intervene in order to permit the emergence of some particular soul looks very much like it might be some kind of infringement on divine freedom and sovereignty." But since there cannot be a soul which is not a particular soul, a foetus-soul law could not operate so as to produce a particular soul chosen by God, unless God not merely sustained the law in operation but determined its particular outcome-which is what Hasker suggests in his footnote 10. Since, almost all philosophers agree, it is not a constraint on God that he cannot do the logically (and so metaphysically) impossible, I cannot see why it being logically necessary that in order to bring about the existence of particular souls by means of laws of nature God has to be active in the operation of each particular law, constitutes "some kind of infringement on divine freedom and sovereignty." In willing the end (the existence of a particular human soul) necessarily God wills any logically necessary means to achieve that end. However, it is not logically (or metaphysically) necessary that, in order to bring about the existence of souls, God should operate through laws of nature. There remains the possibility that God might act directly so as to cause the existence of each particular soul when a foetus reaches a certain stage of development without doing so through the operation of laws of nature. I left this possibility open by writing, as Hasker noted, "if there is to be a scientific explanation for the coming into existence of human souls," there must be some law of nature of the kind I have just described. However, the predictable regularity of the causation of souls by foetuses at a certain stage development makes it very probable that souls are produced by a law-governed process, and so- given that God causes the existence of souls- 
he does it by being active within the operation of the soul-producing law. And if that involves postulating a very strange kind of law, so too does the naturalistic alternative which I described in the previous section. (I add that it does not seem to me a problem if God needs to provide souls for "bees and wasps." If this is a problem for theism, it would be a problem also for naturalism which would need to postulate laws which by chance cause the existence of particular invertebrate souls. But I argue (167) that it is improbable that invertebrates are conscious, and so it is improbable that they have souls.)

\section{BIBLIOGRAPHY}

Chalmers, David. "Does Conceivability Entail Possibility?" In Conceivability and Possibility, edited by Tamar Sz. Gendler and John Hawthorne, 145-200. Oxford: OUP, 2002.

Fine, Kit. "Essence and Modality." Philosophical Perspectives 8 (1994): 1-16.

PARFIT, Derek. Reasons and Persons. Oxford: OUP, 1984.

SWInBuRne, Richard. The existence of God. 2nd ed. Oxford: OUP, 2004.

Swinburne, Richard. Mind, Brain, and Free Will. Oxford: OUP, 2013.

RESPONSE TO ESSAYS ON ARE WE BODIES OR SOULS?

Sum mary

This paper consists of my responses to the comments by nine commentators on my book Are we Bodies or Souls? It makes twelve separate points, each one relevant to the comments of one or more of the commentators, as follows: (1) I defend my understanding of "knowing the essence" of an object as knowing a set of logically necessary and sufficient conditions for an object to be that object; (2) I claim that there cannot be thoughts without a thinker; (3) I argue that my distinction of "mental" from "physical" events in terms of whether anyone has privileged access to whether or not they occur, is a clear one; (4) and (5) I defend my account of metaphysical modality and its role in defending my account of personal identity; (6) I defend my view that Descartes's argument in favor of the view that humans are essentially souls fails, but that my amended version of that argument succeeds; (7) I claim that my theory acknowledges the closeness of the connection in an earthly life between a human soul and its body; (8) I argue that my Cartesian theory of the soul-body relation is preferable to Aquinas's theory of that; (9) I argue that a material thing cannot have mental properties; (10) I argue that any set of logically necessary conditions for an object to be the object it is, which together form a logically sufficient condition for this, mutually entails any other such set; (11) I deny that a dualist needs to provide an explanation of how the soul has the capacities that it has; and finally (12) I defend my view that souls have thisness, and claim that that is not a difficulty for the view that God determines which persons will exist.

Keywords: Descartes; essence; personal identity; physical event; mental event; soul. 